\title{
Culture, attitudes, and emotional memory: A complicated relationship
}

Chung, Christie $\square$

Mills College, USA (cchung@mills.edu)

Yip, Abby Pui Wang

Mills College,USA (py78@cornell.edu)

Lin, Ziyong

Mills College,USA (ziyong@umich.edu)

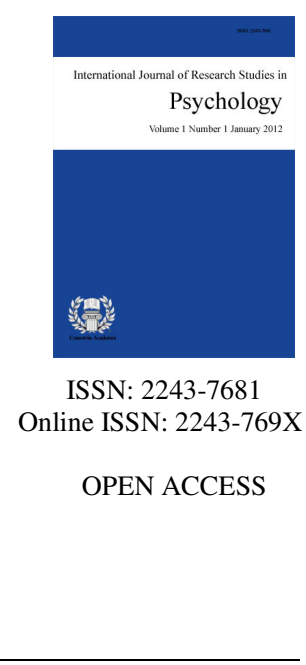

\section{Abstract}

Older adults often remember less negative information than young adults, constituting a positivity effect. In the present study, we examined the effect of culture on this age-related positivity effect and the influence of view of aging on emotional memory by examining culture in two different ways: 1) geographical location and 2) ethnic grouping. We assessed emotional memory recall using an emotional memory picture task (Chung, 2010) and view of aging using a View of Aging Task (Levy \& Langer, 1994). Our results showed that Chinese older adults in China held the most positive view of aging, followed by older adults in Hong Kong, and then Chinese immigrants and Caucasian older adults in the US. Emotional memory performance, however, did not follow the same cultural trajectory. Caucasian US older adults were the only group that recalled more positive pictures than their younger counterparts. All other older groups of East Asian origin showed a more balanced emotional recall rate of positive and negative pictures. These findings not only demonstrate the decoupling of view of aging and emotional memory, but more importantly, suggest that culture as defined by geographical location and ethnic grouping indeed yield different findings in attitudes and cognition - immigrants in the US held similar views of aging to Caucasian US participants (same location), but was in fact more similar in performance to the other two Asian groups in emotional memory recall (same ethnic grouping).

Keywords: positivity effect; culture; emotional memory; view of aging 


\section{Culture, attitudes, and emotional memory: A complicated relationship}

\section{Introduction}

In recent years, many studies have compared age-related emotional and cognitive changes cross-culturally, especially between Western, independent cultures such as the US, and Eastern, interdependent cultures such as China (e.g., Chung \& Lin, 2012; Fung, 2013; Kwon, Schiebe, Samanez-Larkin, Tsai, \& Carstensen, 2009). This West vs. East contrast is especially interesting given the relatively negative view on aging in the West based on individualistic and youth-oriented values (e.g., Crockett \& Hummert, 1987; Kite \& Johnson, 1988), and the more positive views of old age in the East due to Confucian and filial piety traditions (Giles, McCann, Ota, \& Noels 2002; Levy \& Langer, 1994; Valdez, Angeles, Pareja-Corpuz, \& Hernandez, 2013). Yet, one important question that has not been systematically addressed in the emotional memory literature is how culture should be defined. Shall we examine people who live in different geographical locations, or shall we examine culture based on ethnic grouping within the same geographical location? Although both approaches have been utilized in past studies, not one study to date has compared these two methods. In the present study, we tested young and older adults' emotional memory patterns in three different geographical locations worldwide and also tested two different ethnic groups within the US. We collected data from: 1) young and older Caucasian and Chinese adults in the US (West); 2) young and older adults in Canton, China (East); and 3) Hong Kong, an international entre port, that has been under British rule from 1897 to 1997 (East and West).

\section{Literature Review}

\subsection{The age-related positivity effect: Socioemotional Selectivity Theory}

A growing literature suggests that older adults place greater emphasis on processing and remembering positive information than young adults (Mather \& Carstensen, 2005; Carstensen, Turan, Scheibe, Ram, Ersner-Hershfield, Samanez-Larkin, Brooks, \& Nesselroade., 2011). For example, Charles, Mather, and Carstensen (2003) found that older adults remembered significantly fewer negative pictures than young adults on a picture memory task. Mather and Carstensen (2003) found that older adults not only attend less to negative faces during encoding, but also subsequently recall fewer of the negative stimuli compared to positive faces. Although most of the original positivity effect results were found in Western countries, recent studies have extended this effect to Eastern countries such as Korea (Kwon et al., 2009) and China (Chung \& Lin, 2012). Conversely, Fung, Lu, Goren, Isaacowitz, Wadlinger, and Wilson (2008) did not reveal an age-related positivity effect in HK. In the present study, we extended this cross-cultural positivity effect investigation by comparing emotional memory patterns in three regions of the worlds (US, China, and HK), as well as more than one ethnic group within the US (Caucasian and Chinese).

Socioemotional Selectivity Theory (SST) is one of the most prominent US theories used to explain the positivity effect in old age. According to SST, when one's lifetime is perceived to be limited, emotionally meaningful thoughts, for example viewing the past as positive, are emphasized more than thoughts directed toward gaining new information (Carstensen, 1993, 2006; Carstensen, Pasupathi, Mayr, \& Nesselroade, 2000; Carstensen \& Mikels, 2005; Reed \& Carstensen, 2012). Thus, older adults are more likely than young adults to prioritize spending time with close family and friends (Fung, Carstensen, \& Lutz, 1999). Older adults are also more likely to process information that is meaningful based on their limited cognitive resources. This preference usually translates into a positivity effect in memory and attention, given that most people prefer positive over negative emotion (Carstensen, 1993, 2006; Reed \& Carstensen, 2012).

Apart from observing a positivity effect in memory, researchers have found a similar positivity bias, or 
reduced negativity effect, in other paradigms, such as first impression of materials (Zebrowitz, Franklin, Hillman, \& Boc, 2012), reviewing past choices (Mather \& Johnson, 2000), autobiographical information (Field, 1981; Kennedy, Mather, \& Carstensen, 2004; Schlagman, Schulz, \& Kvavilashvili, 2006; Wagenaar \& Groeneweg, 1990; Tomaszczy \& Fernandes, 2012) and perspective taking (Sullivan, Mikels, \& Carstensen, 2010; Lynchard \& Radvansky, 2012). Older adults who had higher cognitive functioning ability were more likely to show a positivity effect, pointing to the importance of cognitive control in the process of inhibiting negative thought processes (Mather \& Knight, 2005). Although several other studies have documented a lack of such a positive effect in aging (e.g. Comblain, D'Argembeau, Van der Linden, \& Aldenhoff, 2004; Kensinger, Brierly, Medford, Growdon, \& Corkin, 2002), abundant evidence suggests that older adults process emotional information differently from young adults. Yet, most of these studies have focused on the influence of neurological and cognitive age-related changes on emotional memory. The present study takes a unique cross-cultural perspective to expand our current understanding of age-related emotional memory and the applicability of the widely cited theories throughout the Western world.

\subsection{Cross-cultural examination of the positivity effect}

As mentioned in previous studies (Chung \& Lin, 2012), Western and Eastern views of aging could be rather different. In general, older adults in the East have been found to hold a much more positive outlook on aging compared to their Western counterparts. In the present study, we examined participants' view of aging and emotional memory patterns in Canton, China - a part of the Eastern world that is still rather traditional and heavily influenced by Confucian thoughts; in California and Massachusetts, US - a place represented by strong Western values, and in HK - a special administrative area in China that was under British rule for 100 years, and therefore, represents a medium between the East and the West. We also tested both Caucasian and Chinese older adults in the US to examine whether ethnic grouping in the same geographical location may contribute to different emotional memory effects.

Recent development in the area of cross-cultural brain research suggests that culture shapes the way we process and remember information (Fung, 2013; Tohidian \& Tabatabaie, 2010). Thus, cross-cultural examination of emotional memory is not only interesting but essential in our understanding of the fast growing aging population in the world. Kwon et al. (2009) extended the positivity effect to Korean participants (tested in Korea) using an emotional picture memory task. Although cultural differences did emerge in the valence ratings of the pictures, the positivity bias remained once this difference was controlled. Chung and Lin (2012) also found a positivity effect in Chinese participants (tested in Canton, China), although the patterns of memory were different between the two countries. US older adults remembered more positive pictures than US young adults; but China older adults remembered fewer negative pictures than their younger counterparts. Ratings of the pictures were similar between participants from the two countries. Thus, although a positivity effect was found in both Korea and China, cultural differences in processing or remembering of the emotional stimuli remained.

Other studies revealed mixed findings. For example, Fung et al. (2008) found that older adults from HK did not show a positivity bias in an attentional, eye-tracking experiment utilizing faces as stimuli. Fung et al. (2008) explained that although a "positivity effect" was not found, their findings were consistent with SST. Emotional meaningfulness vary widely across cultures, especially between independent (e.g., Western cultures that value independence, autonomy, and uniqueness) and interdependent (e.g., East Asian cultures that emphasize the self as part of a whole community) cultures. Westerners tend to put much more emphasis into processing positive emotions, while East Asian cultures consider ideal feelings to include both negative and positive emotions (Fung, 2013). For example, Uchida and Kitayama (2009) found that Americans only described positive features when asked to explain the construct "happiness". Japanese participants, on the other hand, described both positive and negative features.

Reed and Carstensen (2012) and Fung (2013) further addressed the lack of a positivity effect in Fung et al.'s (2008) study. Both articles documented that the exhibition of the age-related positivity effect does not merely 
depend on the valence of positive material, but rather the meaning attached to positive information. If cultures value positive and negative materials differently, the subsequent emotional memory pattern of people from these cultures will also differ, despite a similar underlying neurological/cognitive mechanism.

\subsection{The present study}

Although the examination of cross-cultural generalizability of the age-related positivity effect has begun (e.g., Chung \& Lin, 2012; Kwon et al., 2009), the relation between culturally-based views of aging and emotional memory have not yet been explored systematically. As previous studies on culture and cognition suggests, view of aging may shape the way memory is processed. In the present study, we utilized an emotional memory task (Chung, 2010) and a view of aging task (Levy \& Langer, 1994) to further examine the relation between these two factors. In Chung and Lin (2012), it was found that Chinese older adults held significantly more positive views of aging than their young counterparts, and US young and older participants. In order to further understand how culture affects cognition, we added Hong Kong (HK) as a testing location due to its Westernized culture, but Eastern location; as well as added a Chinese group in the US due to the participants' East Asian roots but Westernized geographical living location. We predicted that Chinese older adults, regardless of geographical location, would hold a more positive view of aging compared to HK and US Caucasian participants. As for emotional memory performance, the literature points to the finding of a more balanced emotional profile, i.e., similar recall rates for positive, neutral, and negative information, in interdependent cultures (Fung, 2013). Thus, we predicted the strongest age-related positivity effect in our US Caucasian participants compared to all other groups.

\section{Methods}

\subsection{Participants}

Forty-six Caucasian young adults (27 women, 19 men; mean age $=21.41$, range $=18$ to 31$)$ and 49 Caucasian older adults ( 40 women, 9 men; mean age $=72.51$, range $=55$ to 87 ) participated in our study in the US. Twenty Chinese immigrant young adults ( 8 women, 12 men, mean age $=22$, range $=18$ to 34 ) and 28 Chinese immigrant older adults ( 14 women, 14 men; mean age $=75.57$, range $=56$ to 87 ) also participated in the US. Forty Chinese young adults ( 18 women, 22 men; mean age $=20.70$, range $=19$ to 22 ) and 40 Chinese older adults ( 29 women, 11 men; mean age $=69.53$, range $=55$ to 83) participated in Canton, China. Thirty-one Chinese young adults ( 16 women, 15 men; mean age $=20.56$, range $=18$ to 29 ) and 22 Chinese older adults (13 women, 9 men; mean age $=66.72$, range $=55$ to 71) participated in Hong Kong (HK). Participants were reimbursed $\$ 10 /$ hour for participation and the experimental session lasted about an hour. All participants were tested individually in their native languages: English for the US participants, Mandarin or Cantonese for the immigrant and Chinese participants, and Cantonese for the HK participants.

Testing sessions took place in a quiet room with a 15-inch PC laptop computer. Young US participants were tested at Massachusetts Institute of Technology (M.I.T.), and the older US participants were tested at Mills College and aging communities in the San Francisco Bay Area. Immigrant adults were tested in aging communities in Berkeley and Oakland, California. Young and older Chinese participants were all tested in Canton, China either at the Guangzhou higher Education Mega Center, or in a quiet room at the participants' home. Young and older HK adults were tested in an isolated environment at the participants' home. All participants were equated on health condition (demographics and self-report health questionnaire), education level ( $\geq 12$ years), dementia status: Mini Mental State Examination for older adults (MMSE; Cockrell \& Folstein, 1988), and depression status: Beck Depression Inventory (BDI; Beck, Ward, Mendolson, Mock, \& Erbaugh, 1961). MMSE score of less than 27 indicates possibility of mild cognitive impairment, and BDI score of more than 10 indicates the possibility of mild depression. We, therefore, screened out participants who scored over 10 on BDI and less than 27 on MMSE. 
Our final analysis included 43 Caucasian young adults (25 women, 18 men) and 36 Caucasian older adults ( 29 women, 7 men) from the US; 15 immigrant young adults ( 6 women, 9 men) and 26 immigrant older adults (13 women, 13 men) in the US; 16 young adults ( 8 women, 8 men) and 39 older adults ( 28 women, 11 men) from China; as well as 25 young adults (12 women, 13 men) and 22 older adults (13 women, 9 men) from HK. Many young Chinese participants were excluded because their BDI scores were not collected when we first started conducting testing in China. As seen from Table 1,US Caucasian young adults had significantly fewer years of education than Caucasian older adults, $t(75)=4.30, p<.01$. However, the reverse pattern was found in the Chinese and the immigrants groups: Although the differences were not statistically significant, Chinese older adults had fewer years of education than Chinese young adults, $t(53)=1.49, p=.14$, and older Chinese immigrants in the US also received less education than younger immigrants, $t(39)=1.86, p=.07$. This is probably a result of the Cultural Revolution in China (1966-1976) that banned intellectual pursuits. On the other hand, HK was a British colony for 100 years, and therefore, HK older adults were not affected by the Communist regime in China. This explains why most HK older adults received significantly more years of education than their Chinese counterparts, $t(58)=2.56, p<.05$. See Table 1 for other significant differences. Overall, young adults performed significantly better than older adults on the digit span backward task, and Chinese speaking adults had higher performance on digit span task than English speaking participant as documented in the psychological literature (Hoosain \& Salili, 1988; see Table 1).

\section{Table 1}

Means and standard deviations for demographic and cognitive measures

\begin{tabular}{|c|c|c|c|c|c|}
\hline Measure & Age & $\begin{array}{c}\text { Years of } \\
\text { Education }\end{array}$ & MMSE & $\begin{array}{l}\text { Digit Forward } \\
\text { Score }\end{array}$ & $\begin{array}{c}\text { Digit Backward } \\
\text { Score }\end{array}$ \\
\hline $\begin{array}{l}\text { US Young Adults } \\
(n=43)\end{array}$ & $\begin{array}{l}21.23 \\
\text { Range: } 18-27\end{array}$ & $\begin{array}{l}14.98 \\
(1.87)\end{array}$ & $\begin{array}{l}29.40 \\
(.76)\end{array}$ & $\begin{array}{l}12.67 \\
(2.24)\end{array}$ & $\begin{array}{l}8.70 \\
(2.76)\end{array}$ \\
\hline $\begin{array}{l}\text { US Older Adults } \\
(n=36)\end{array}$ & $\begin{array}{l}72.83 \\
\text { Range: } 55-87\end{array}$ & $\begin{array}{l}17.18 * * \\
(2.61)\end{array}$ & $\begin{array}{l}28.81 * * \\
(1.06)\end{array}$ & $\begin{array}{l}10.58 * * \\
(2.10)\end{array}$ & $\begin{array}{l}6.08 * * \\
(2.03)\end{array}$ \\
\hline $\begin{array}{l}\text { Young Chinese } \\
\text { US Immigrants } \\
(n=15)\end{array}$ & $\begin{array}{l}22.40 \\
\text { Range: } 18-34\end{array}$ & $\begin{array}{l}15.93 \\
(2.96)\end{array}$ & $\begin{array}{l}29.93 \\
(0.26)\end{array}$ & $\begin{array}{l}15.33 \\
(0.98)\end{array}$ & $\begin{array}{l}10.40 \\
(3.50)\end{array}$ \\
\hline $\begin{array}{l}\text { Older Chinese } \\
\text { US Immigrants } \\
(n=26)\end{array}$ & $\begin{array}{l}76.46 \\
\text { Range: } 59-87\end{array}$ & $\begin{array}{l}13.42 * * \\
(4.71)\end{array}$ & $\begin{array}{l}29.54 \\
(0.81)\end{array}$ & $\begin{array}{l}13.85^{*} \\
(2.46)\end{array}$ & $\begin{array}{l}7.19 * * \\
(2.77)\end{array}$ \\
\hline $\begin{array}{l}\text { HK Young Adults } \\
(n=25)\end{array}$ & $\begin{array}{l}20.72 \\
\text { Range: } 18-29\end{array}$ & $\begin{array}{l}14.28 \\
(1.10)\end{array}$ & $\begin{array}{l}29.56 \\
(0.77)\end{array}$ & $\begin{array}{l}15.48 \\
(.92)\end{array}$ & $\begin{array}{l}11.12 \\
(2.56)\end{array}$ \\
\hline $\begin{array}{l}\text { HK Older Adults } \\
(n=22)\end{array}$ & $\begin{array}{l}60.62 \\
\text { Range: } 55-71\end{array}$ & $\begin{array}{l}15.29 \\
(2.94)\end{array}$ & $\begin{array}{l}29.05 \\
(1.00)\end{array}$ & $\begin{array}{l}15.14 \\
(1.21)\end{array}$ & $\begin{array}{l}7.45 * * \\
(3.04)\end{array}$ \\
\hline $\begin{array}{l}\text { Chinese Young Adults } \\
(n=16)\end{array}$ & $\begin{array}{l}20.88 \\
\text { Range: } 20-22\end{array}$ & $\begin{array}{l}14.13 \\
(.81)\end{array}$ & -- & $\begin{array}{l}15.44 \\
(.81)\end{array}$ & $\begin{array}{l}8.94 \\
(3.40)\end{array}$ \\
\hline $\begin{array}{l}\text { Chinese Older Adults } \\
(n=39)\end{array}$ & $\begin{array}{l}69.44 \\
\text { Range:55-83 }\end{array}$ & $\begin{array}{l}12.26 \\
(4.97)\end{array}$ & $\begin{array}{l}29.23 \\
(1.04)\end{array}$ & $\begin{array}{l}14.74 \\
(1.48)\end{array}$ & $\begin{array}{l}5.87 * * \\
(2.46)\end{array}$ \\
\hline
\end{tabular}

\subsection{Materials}

Participants first completed a demographics and health questionnaire, before the administration of the MMSE, a 30-item questionnaire to assess their cognitive functioning. We then asked participants to look at 30 pictures (10 positive, 10 neutral, and 10 negative) one at a time on a computer screen as if they were watching 
television. These pictures were presented at a rate of 4 sec/picture, with 2 fillers in the beginning and at the end of each encoding list, i.e., an incidental memory test. This picture memory task consisted of photos of objects and scenes and was standardized in several previous experiments on emotional memory (Chung, 2010, 2012). After the encoding phase, participants were given the digit span forward and backward tasks (Wechsler Adult Intelligent Scale; Wechsler, 1997), where participants were told to repeat a string of digits either in the same or reverse order as presented by the experimenter. This task was used to create a delay of about 5 minutes between encoding and recall. Then, they were asked to recall as many of the pictures as they could remember using verbal labels, e.g., a waterfall. The experimenter recorded all responses in writing.

The View of Aging task (Yoon, Hasher, Feinberg, Rahhal, \& Winnocur, 2000) was then administered, in which participants wrote down 5 words or phrases that came to mind when they thought of old age on a blank piece of paper. Participants were then given the BDI (Beck et al., 1961) and the Rasch modeled memory self-efficacy scale (Zelinski \& Gilewski, 2004), a meta-memory questionnaire where they had to rate their general frequency of forgetting. The WAIS vocabulary test (Wechsler, 1997) was completed at the end of the session, in which young adults gave verbal synonyms or definitions to various English words.

\section{Results}

\subsection{View of Aging}

Eight independent raters, two for each cultural group, assessed the View of Aging data from the US, Chinese immigrants, China, and HK participants using the following valance scale: $0=$ negative, $0.5=$ neutral, $1=$ positive. Their results had high reliability ( $r$ 's $>.90, p$ 's $<.01)$. See Table 2 for means, s.d.'s, and final $n$ 's in each cell. As we predicted, Chinese older adults held the most positive view of aging $(M=.88)$, followed by HK $(M$ $=.59)$, Chinese immigrants $(M=.46)$, and US older adults $(M=.44)$. A two-way ANOVA revealed a significant interaction between age and location, $F(2,197)=6.00, p<.01, \eta^{2}=.057$. There was a significant main effect of age, $F(1,197)=31.35, p<.01, \eta 2=.13$, and a significant main effect of location, $F(2,197)=7.75, p<.01, \eta 2$ $=.07$. Also, Chinese older adults had significantly more positive views of aging than their age counterparts in the US group, $t(60)=6.50$, in the immigrants group, $t(51)=5.74, \mathrm{p}<.01$, as well as in the HK group, $t(46)=3.86$, $\mathrm{p}<.01$. HK older adults viewed aging marginally more positively than US adults, $t(56)=1.63, p=.10$. Young adults' view of aging were in general negative, and did not differ by location (US $M=.39$, China $M=.42$, HK $M$ $=.27$, Immigrants $M=.44)$. Chinese older adults viewed aging significantly more positively than Chinese young adults, $t(40)=7.33, p<.01$, and a similar age difference was found in HK, $t(45)=3.39, p<.01$. US and Chinese immigrants older and younger adults, however, did not view aging significantly differently, $t(71)=.73, p>.05$ and $\mathrm{t}(40)=.29, p>.05$.

\section{Table 2}

View of Aging valence ratings for young and older participants in US, China, and Hong Kong

\begin{tabular}{|c|c|c|c|c|c|c|c|c|}
\hline Location & \multicolumn{2}{|c|}{ US } & \multicolumn{2}{|c|}{ Immigrants } & \multicolumn{2}{|c|}{ China } & \multicolumn{2}{|c|}{ Hong Kong } \\
\hline Group & $\begin{array}{l}\text { Young } \\
(n=37)\end{array}$ & $\underset{(n=36)}{\text { Old }}$ & $\begin{array}{l}\text { Young } \\
(n=15)\end{array}$ & $\begin{array}{c}\text { Old } \\
(n=26)\end{array}$ & $\begin{array}{l}\text { Young } \\
(n=16)\end{array}$ & $\begin{array}{l}\text { Old } \\
(n=27)\end{array}$ & $\begin{array}{l}\text { Young } \\
(n=25)\end{array}$ & $\begin{array}{c}\text { Old } \\
(n=22)\end{array}$ \\
\hline $\begin{array}{l}\text { Valence } \\
\text { rating }\end{array}$ & $\begin{array}{l}0.39 \\
(.20)\end{array}$ & $\begin{array}{l}0.44 \\
(.33)\end{array}$ & $\begin{array}{l}0.44 \\
(.17)\end{array}$ & $\begin{array}{l}0.46 \\
(.34)\end{array}$ & $\begin{array}{c}0.42 * \dagger \\
(.26)\end{array}$ & $\begin{array}{c}0.88 * * \\
(.15)\end{array}$ & $\begin{array}{c}0.27 \dagger \dagger \\
(.29)\end{array}$ & $\begin{array}{l}0.59 \\
(.36)\end{array}$ \\
\hline
\end{tabular}

\subsection{Emotional Memory Patterns}

Figure 1 shows the emotional memory results displayed by young and older adults in the US, Chinese immigrants, China, and HK groups. The data was analyzed in a 2 (Age: young, old) X 3(Valence: positive, 
neutral, negative) X 3 (Location: US, China, HK) X 2 (ethnicity) mixed factor ANOVA. Although the four-way interaction was non-significant, the three-way interaction among age, valence, and location achieved statistical significance, $F(2,169)=3.24, p<.05, \eta^{2}=.037$. The two-way interaction between valence and age was also significant, $F(2,169)=13.05, p<.01, \eta^{2}=.13$. We also found a significant main effect of valence, $F(2,169)=$ $64.08, p<.01, \eta^{2}=.43$, and a marginally significant main effect of location, $F(1,170)=3.65, p=.06, \eta^{2}=.21$. Participants remembered significantly more positive pictures than neutral pictures, $M \mathrm{~s}=3.08$ vs. $2.41, t(222)=$ $4.84, p<.01$, and also more negative pictures than positive and neutral pictures, $M \mathrm{~s}=4.00$ vs. $3.08, t(222)=$ $10.83, p<.01$ and $M \mathrm{~s}=4.00$ vs. $2.41, t(222)=6.18, p<.01$. Participants in China remembered more pictures in total than those in the US, $M \mathrm{~s}=10.62$ vs. 9.35 .

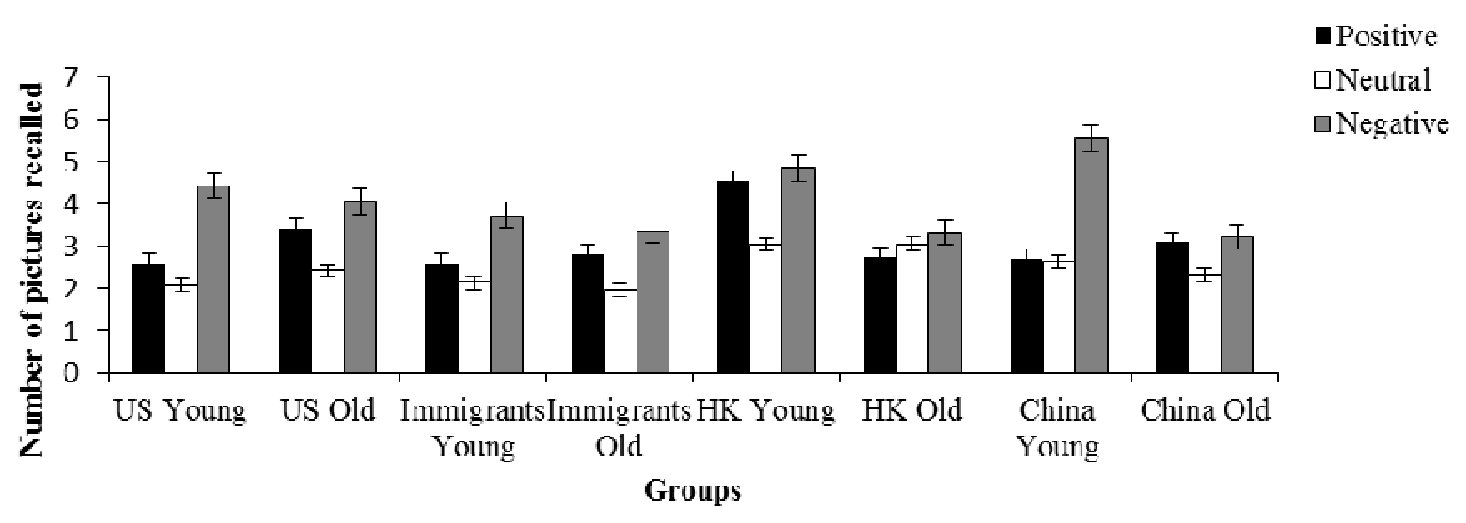

Figure 1. Mean number of positive, neutral, and negative pictures recalled for US and Chinese young and older adults

We conducted further analyses to examine the significant age $\mathrm{x}$ valence $\mathrm{x}$ location three-way interaction. In the US, the interaction between valence and age group was significant, $F(2,118)=3.96, p<.05, \eta^{2}=.06$. Young adults remembered significantly more negative pictures than older adults, $M \mathrm{~s}=4.24$ vs. 3.76, $t(119)=2.07, p$ $<.05$. After breaking the data down by age group, results revealed that young participants remembered significant more negative than positive and neutral pictures, $M \mathrm{~s}=4.24$ vs. $2.59, t(57)=6.26, p<.01$ and $M \mathrm{~s}=$ 4.24. vs. $2.10, t(57)=8.27, p<.001$, respectively. Young participants also recalled significantly more positive than neutral pictures, $M \mathrm{~s}=2.59$ vs. $2.10, t(57)=2.21, p<.05$. Older participants remembered significantly more positive and negative pictures than neutral pictures, $M \mathrm{~s}=3.16$ vs. $2.24, t(62)=3.77, p<.01$ and $M \mathrm{~s}=3.76$ vs. $2.24, t(62)=5.69, p<.001$, respectively. Older participants also recalled significantly more negative than positive pictures, $M \mathrm{~s}=3.76$ vs. $3.16, t(62)=2.31, p<.05$. Although the four-way interaction of ethnicity, age, valence, and location was not significant, we would like to point out that US Caucasian and US immigrant adults did show a slight difference in their cognitive performance based on a priori interests. US Caucasian participants displayed the well-documented positivity effect as older participants recalled significantly more positive pictures than their young counterparts, $M \mathrm{~s}=3.24$ vs. $2.59, t(147)=2.56, p<.02$. Chinese immigrants, however, did not show a difference in recall pattern between the two age groups, thus, no positivity effect was observed.

In China, the two-way interaction between valence and age group was significant, $F(2,52)=10.84, p<.001$, $\eta^{2}=.294$. Young adults remembered significantly more negative pictures than older adults, $M \mathrm{~s}=5.56$ vs. 3.21 , $t(53)=4.72, p<.01$. Young participants remembered significantly more negative than positive pictures, $M \mathrm{~s}=$ 5.56 vs. $2.69, t(15)=7.06, p<.01$, and more negative than neutral pictures, $M$ s $=5.56$ vs. $2.63, t(15)=6.79, p$ $<.01$. Older participants recalled significantly more positive than neutral pictures, $M \mathrm{~s}=3.08$ vs. $2.31, t(38)=$ $2.63, p=.01$; as well as more negative than neutral pictures, $M \mathrm{~s}=3.21$ vs. $2.31, t(38)=2.78, p<.01$.

In HK, the significant two-way interaction between valence and age group was also significant, $F(2,44)=$ $3.41, p<.05, \eta^{2}=.14$. Young adults remembered significantly more positive and negative pictures than older adults, $M \mathrm{~s}=4.56$ vs. $2.73, t(45)=3.74, p=.01$ and $M \mathrm{~s}=4.84$ vs. $3.32, t(45)=3.30, p<.01$, respectively. Young 
adults remembered significantly more positive and negative pictures than neutral pictures, $M \mathrm{~s}=4.56$ vs. 3.04 , $t(24)=2.52, \mathrm{p}<.05$ and $M \mathrm{~s}=4.84$ vs. $3.04, t(45)=3.03, p<.01$, respectively. On the contrary, HK older adults' memory performance did not significantly differ among the three categories. Therefore, although HK young adults showed an emotional enhancement effect, an age-related positivity effect was not found. See Table 3 for details on individual contrasts.

\section{Table 3}

A table summarizing the mean numbers and standard deviations of recalls for positive, negative, and neutral images by China, US, and HK young and older adults

\begin{tabular}{l|lll}
\hline \multirow{2}{*}{ Groups } & \multicolumn{3}{c}{ Pictures recalled } \\
\cline { 2 - 4 } & Positive & Neutral & Negative \\
\hline US Young & $2.58 \dagger(1.50)$ & $2.09(1.27)$ & $4.42(1.83)$ \\
US Old & $3.42(1.73)$ & $2.44(1.97)$ & $4.06(1.90)$ \\
Immigrants Young & $2.60(.99)$ & $2.13(1.55)$ & $3.73(1.10)$ \\
Immigrants Old & $2.81(1.47)$ & $1.96(1.79)$ & $3.37(2.00)$ \\
HK Young & $4.56 \dagger \dagger(1.98)$ & $3.04(1.77)$ & $4.84 \dagger \dagger(1.84)$ \\
HK Old & $2.73(1.24)$ & $3.05(1.43)$ & $3.32(1.21)$ \\
China Young & $2.69^{* *(1.50)}$ & $2.63^{*}(1.46)$ & $5.56^{* * \dagger \dagger(1.55)}$ \\
China Old & $3.08(1.50)$ & $2.31(1.15)$ & $3.21^{*}(1.74)$ \\
\hline
\end{tabular}

Note. Difference between US, Immigrants, China, and Hong Kong age counterparts: $* p<.05$, ** $p<.01$; difference between young and old within each location: $\dagger p<.05, \dagger \dagger p<.01$

Correlation and regression analyses between view of aging and emotional memory data revealed non-significant relationships between the two variables. These results suggest that culture has differential effects on views of aging and cognition, but the two domains may not interact as much as we predicted.

\section{Discussion}

Our findings extended the examination of the effect of culture on age-related memory that began in Chung \& Lin (2012). We found support for our hypotheses regarding view of aging: Chinese older adults held the most positive view of aging, followed by Hong Kong (HK), Chinese immigrants, and US older adults. This progression in view of aging is exactly what one would expect with the Westernized stereotype of aging negativity. Emotional memory processing, however, did not follow the same cultural trajectory. The well-documented positivity effect in old age was observed in the US and China, albeit different patterns (Chung \& Lin, 2012). This finding converges with other research studies such as Kwon et al. (2009). However, HK older adults and Chinese immigrants did not show an age-related positivity effect. This finding is similar to Fung et al.'s (2008) results and may be explained by the hypothesis that interdependent cultures favor ideals of equating positive and negative information in order to achieve a balance in emotions (Fung et al., 2008; Fung, 2013; Reed \& Carstensen, 2012). With closer examination, Chinese older adults also showed evidence of balanced emotional memory similar to HK and immigrant older adults, as they remembered similar numbers of positive and negative pictures (fewer neutral, however). Although these findings may seem different from our hypotheses, they are in fact compatible with SST and the historical context of HK.

\subsection{Cross-cultural effects}

Although close in geographic proximity, China and HK differed vastly politically and culturally. HK's 100 years of British rule (1897-1997) had much impact on the way the society evolved. HK is an international entre port, thus, many may consider it much more Westernized than China. This westernization might explain the more negative view of aging we found in the present study. However, in consideration of Chinese history, HK was one of the places to which many Chinese scholars (now older adults) escaped during the Chinese Cultural Revolution (1966-1976). Thus, many of the scholarly and cultural traditions that were banned in the Chinese revolution era were preserved in HK. This interesting historical background may explain the more prominent balance in emotional memory processing in HK than in in Canton, China observed in our present study. 
The immigrants in the US, on the other hand, were mostly from mainland China. This would explain their similarity in demographics as well as emotional memory patterns to our Chinese participants. This finding is impressive because although older immigrants in our study showed a negative view of aging score more similar to those of US Caucasian older adults than to Chinese older adults, their emotional memory performance was much closer to that of their Chinese counterparts. This unique finding suggests that cognitive processing may be less malleable than view of aging or attitudes in general. This finding is crucial as we further research the effect of culture on issues related to aging and cognition.

Fung et al. (2008), Reed and Carstensen (2012), and Fung (2013) all emphasized that the positivity effect is not the only way for age-related emotional regulation to manifest itself. Different cultural norms may assign different emotional significance to items, events, and people. Therefore, our findings illustrate the differences in emotional preference rather than in emotional regulation. In fact, research has shown that Eastern cultures place much more emphasis on balancing emotions than do Western cultures. Independent cultures, e.g., encourage people to attain positive emotions, so as to keep a high sense of optimism and self-esteem. Success is often defined by the positive characteristics of achievements and feelings. In contrast, interdependent cultures focus more on how an individual may fit into a society. Optimism and self-esteem are therefore less important. People in interdependent cultures, e.g., China, are much more likely to pay attention to negativity in their surroundings to avoid social mishaps (Kitayama \& Karasawa, 1995). The present study demonstrated that although immigrants live in the US, the only thing that is affected by their living location is view of aging and not emotional memory processing. When examined carefully, the three Chinese groups performed more similarly to one another than to the Caucasian US participants. This finding suggests that geographical location greatly affects people's view of aging, but cognitive emotional processing may not be affected by culture in the same way. Our results suggest that ethnic grouping rather than geographical location may be a better predictor of emotional memory performance, while the opposite may be true for attitudes-related factors.

\subsection{Implication and future directions}

The non-significant correlation between view of aging and emotional memory processing suggest that view of aging is not an important factor in SST and emotional processing in old age. SST postulates that as people approach endings, they tend to regulate their emotions to focus on emotionally meaningful information. Therefore, their view towards life in old age is not as important as their view towards death - the ultimate ending older adults are facing. Therefore, our future studies will focus on examining the impact of view on life after death on emotional regulation and cognition.

Yet, one important implication this finding conveys that begs further research is the possibility that the negative stereotype of aging in the Western cultures may be the driving force behind the strong motivation for processing and retaining positive information in old age. Past studies have found that older adults who are cognitively sound are more likely to exhibit the positivity effect (Mather \& Knight, 2005), which converges with neurological evidence that has shown that this emotional processing pattern is indeed an effortful process (Samanez-Larkin \& Carstensen, 2011). As people prefer positive over negative emotions in most situations, Western older adults, who have internalized the negative aging stereotype, may be much more likely than East Asians to use their limited cognitive resources to process positive rather than negative information.

\section{Conclusions}

The decoupling of view of aging and emotional memory results suggest that although culture affects emotional processing and aging attitudes, the relationship between attitudes and memory is much more complicated than we predicted. Our results also suggest that culture defined by geographical location and ethnic grouping could have differential effects on cognition functioning and attitude formation. Future experiments should examine the fundamental reasons why these differences exist to further elucidate the complex relationship between culture and social cognition. 


\section{References:}

Beck, A. T., Ward, C. H., Mendolson, M., Mock, J., \& Erbaugh, J. (1961). An inventory for measuring depression. Archives of General Psychiatry, 4, 561-571. http://dx.doi.org/10.1001/archpsyc.1961.01710120031004

Carstensen, L. L. (1993). Motivation for social contact across the life span: A theory of socioemotional selectivity. In J. E. Jacobs (Ed.), Nebraska Symposium on Motivation (pp. 209-254). Lincoln: University of Nebraska Press.

Carstensen, L.L. (2006). The influence of a sense of time on human development. Science, 312, 1913-1915. http://dx.doi.org/10.1126/science. 1127488

Carstensen, L.L., \& Mikels, J.A. (2005). At the intersection of emotion and cognition: Aging and the positivity effect. Current Directions in Psychological Science, 14. 117-121. http://dx.doi.org/10.1111/j.0963-7214.2005.00348.x

Carstensen, L.L., Pasupathi, M., Mayr, U. \& Nesselroade, J. (2000). Emotional experience in everyday life across the adult life span. Journal of Personality and Social Psychology, 79, 644-655. http://dx.doi.org/10.1037/0022-3514.79.4.644

Carstensen, L. L., Turan, B., Scheibe, S., Ram, N., Ersner-Hershfield, H., Samanez-Larkin, G. R., Brooks, K. P., \& Nesselroade, J. R. (2011). Emotional experience improves with age: Evidence based on over 10 years of experience sampling. Psychology and Aging, 26(1), 21-33. http://dx.doi.org/10.1037/a0021285

Charles, S. T., Mather, M., \& Carstensen, L. L. (2003). Aging and emotional memory: the forgettable nature of negative images for older adults. Journal of Experimental Psychology: General, 132, 310-324. http://dx.doi.org/10.1037/0096-3445.132.2.310

Chung, C. (2010). Effects of view of life and selection bias on emotional memory in old age. GeroPsych: The Journal of Gerontopsychology and Geriatric Psychiatry, 23, 161-168. http://dx.doi.org/10.1024/1662-9647/a000019

Chung, C., \& Lin, Z (2012). A cross-cultural examination of the positivity effect in memory: United States vs. China. International Journal of Aging and Human Development, 75(1), 31-44. http://dx.doi.org/10.2190/AG.75.1.d

Cockrell, J. R., \& Folstein, M. F. (1988). Mini-Mental State Examination (MMSE), Psychopharmacology, 24, 689-692.

Comblain, C., D’Argembeau, A., Van der Linden, M., \& Aldenhoff, L. (2004). The effect of ageing on the recollection of emotional and neutral pictures. Memory, 12, 673-684. http://dx.doi.org/10.1080/09658210344000477

Crockett, W. H., \& Hummert, M. (1987). Perceptions of aging and the elderly. In K. Schaie (Ed.), Annual Review of Gerontology and Geriatrics, Vol. 7 (pp. 217-241). New York, NY US: Springer Publishing Co.

Field, D. (1981). Retrospective reports by healthy intelligent elderly people of personal events of their adult lives. International Journal of Behavioral Development, 4, 77-97. http://dx.doi.org/10.1177/016502548100400106

Fung, H. H. (2013). Aging in culture. The Gerontologist, 53, 369-377. http://dx.doi.org/10.1093/geront/gnt024

Fung, H. H., Carstensen, L. L., \& Lutz, A. (1999). The influence of time on social preferences: Implications for life-span development. Psychology and Aging, 14, 595-604. http://dx.doi.org/10.1037/0882-7974.14.4.595

Fung, H. H., Lu, A. Y., Goren, D., Isaacowitz, D. M., Wadlinger, H. A., \& Wilson, H. R. (2008). Age-related positivity enhancement is not universal: Older Chinese look away from positive stimuli. Psychology and Aging, 23, 440-446. http://dx.doi.org/10.1037/0882-7974.23.2.440

Giles, H., McCann, R. M., Ota, H., \& Noels, K. A. (2002). Challenging intergenerational stereotypes across Eastern and Western cultures. In M.S. Kaplan, N.Z. Henkin \& A.T. Kusano (eds.), Linking lifetimes: A global view of intergenerational exchange (pp. 13-28). Honolulu: University Press of America.

Hoosain, R., \& Salili, F. (1988). Language differences, working memory, and mathematical ability. In M. M.Gruneberg, P. E. Morris, \& R. N. Sykes (Eds.), Practical aspects of memory: Current research and 
Culture, attitudes, and emotional memory: A complicated relationship

issues. Clinical and educational implications (vol. 2, pp. 512-517). Chichester: Wiley.

Kennedy, Q., Mather, M., \& Carstensen, L. L. (2004). The role of motivation in the age-related positivity effect in autobiographical memory. Psychological Science, 15, 208-214. http://dx.doi.org/10.1111/j.0956-7976.2004.01503011.x

Kensinger, E. A., Brierley, B., Medford, N., Growdon, J. H., \& Corkin, S. (2002). Effects of normal aging and Alzheimer's disease on emotional memory. Emotion, 2, 118-134. http://dx.doi.org/10.1037/1528-3542.2.2.118

Kitayama, S., \& Karasawa, M. (1995). Self: A cultural psychological perspective. Japanese Journal of Experimental Social Psychology, 35, 133-163. http://dx.doi.org/10.2130/jjesp.35.133

Kite, M. E., \& Johnson, B. T. (1988). Attitudes toward older and younger adults: A meta-analysis. Psychology and Aging, 3, 233-244. http://dx.doi.org/10.1037/0882-7974.3.3.233

Kwon, Y., Schiebe, S., Samanez-Larkin, G. R., Tsai, J. L., \& Carstensen, L. L. (2009). Replicating the positivity effect in picture memory in Koreans: Evidence for Cross-Cultural Generalizability. Psychology and Aging, 24, 748-754. http://dx.doi.org/10.1037/a0016054

Levy, B., \& Langer, E. (1994). Aging free from negative stereotypes: Successful memory in China and among the American deaf. Attitudes and Social Cognition, 66, 989-997.

Lynchard, N. A., \& Radvansky, G. A. (2012). Age-related perspectives and emotion processing. Psychology and Aging, 27, 934-939. http://dx.doi.org/10.1037/a0027368

Mather, M., \& Carstensen, L.L. (2003). Aging and attentional biases for emotional faces. Psychological Science, 14, 409-415. http://dx.doi.org/10.1111/1467-9280.01455

Mather, M., \& Carstensen, L. L. (2005). Aging and motivated cognition: The positivity effect in attention and memory. Trends in Cognitive Sciences, 9, 496-502. http://dx.doi.org/10.1016/j.tics.2005.08.005

Mather, M., \& Johnson, M. K. (2000). Choice-supportive source monitoring: Do our decisions seem better to us as we age? Psychology and Aging, 15, 596-606. http://dx.doi.org/10.1037/0882-7974.15.4.596

Mather, M., \& Knight, M. (2005). Goal-directed memory: The role of cognitive control in older adults' emotional memory. Psychology and Aging, 20, 554-570. http://dx.doi.org/10.1037/0882-7974.20.4.554

Reed, A. E., \& Carstensen, L. L. (2012). The theory behind the age-related positivity effect. Frontiers in Psychology, 3, 339. http://dx.doi.org/10.3389/fpsyg.2012.00339

Samanez- Larkin, G. R., \& Carstensen, L. L. (2011). Socioemotional functioning and the aging brain. In J. Decety \& J. T. Cacioppo (Eds.), The Handbook of Social Neuroscience (pp. 507-521). New York, NY: Oxford University Press.

Schlagman, S., Schulz, J., \& Kvavilashvili, L. (2006). A content analysis of involuntary autobiographical memories: Examining the positivity effect in old age. Memory, 14, 2, 161-175. http://dx.doi.org/10.1080/09658210544000024

Sullivan, S. J., Mikels, J. A., \& Carstensen, L. L. (2010). You never lose the ages you've been: Affective perspective taking in older adults. Psychology and Aging, 25, 229-234. http://dx.doi.org/10.1037/a0018383

Tohidian, I., \& Tabatabaie, S. (2010). Considering the relationship between language, culture and cognition to scrutinize the lexical influences on cognition. Current Psychology: A Journal for Diverse Perspectives on Diverse Psychological Issues, 29(1), 52-70. http://dx.doi.org/10.1007/s12144-010-9072-z

Uchida, Y., \& Kitayama, S. (2009). Happiness and unhappiness in east and west: Themes and variations. Emotion, 9, 441-45. http://dx.doi.org/10.1037/a0015634

Valdez, J. P., Angeles, J., Pareja-Corpuz, E., \& Hernandez, C. (2013). Perceptions towards aging among selected Filipino adults. International Journal of Research Studies in Psychology, 2(3), 89-96. http://dx.doi.org/10.5861/ijrsp.2013.458

Wagenaar, W. A., \& Groeneweg, J. (1990). The memory of concentration camp survivors. Applied Cognitive Psychology, 4, 77-87. http://dx.doi.org/10.1002/acp.2350040202

Wechsler, D. (1997). Wechsler Adult Intelligent Scale-III: Administration and scoring manual. San Antonio, TX: The Psychological Corporation.

Yoon, C., Hasher, L., Feinberg, F., Rahhal, T. A., \& Winocur ,G.(2000). Cross-cultural differences in memory: 
Chung, C., Yip, A. P. W., \& Lin, Z.

The role of culture-based stereotypes about aging. Psychology and Aging, 15, 694-704.

http://dx.doi.org/10.1037/0882-7974.15.4.694

Zebrowitz, L. A., Franklin, R. r., Hillman, S., \& Boc, H. (2013). Older and younger adults' first impressions from faces: Similar in agreement but different in positivity. Psychology and Aging, 28(1), 202-212. http://dx.doi.org/10.1037/a0030927

Zelinski, E. M., \& Gilewski, M. J. (2004). A 10-item Rasch modeled self-efficacy scale. Aging and Mental Health, 8, 293-306. http://dx.doi.org/10.1080/13607860410001709665 